\title{
Physical Properties of Cotton Bolls (GTHH-49)
}

\author{
Alok Gora ${ }^{1 *}$, R. N. Singh ${ }^{2}$ and Jaypalsinh Chavda ${ }^{1}$ \\ ${ }^{1}$ Department of Agricultural Engineeing, C.P. College of Agriculture, Sadarkrushinagar \\ Dantiwada Agricultural University, Sardarkrushinagar - 385 506, Gujarat, India \\ ${ }^{2}$ Director of Research, Sadarkrushinagar Dantiwada Agricultural University, \\ Sardarkrushinagar - 385 506, Gujarat, India \\ *Corresponding author
}

\section{A B S T R A C T}

\begin{tabular}{l} 
Ke y w or d s \\
$\begin{array}{l}\text { Cotton, USA, } \\
\text { Pakistan, } \\
\text { Uzbekistan, Brazil, } \\
\text { kharif crop }\end{array}$ \\
\hline Article Info \\
$\begin{array}{l}\text { Accepted: } \\
\text { 30 May } 2020 \\
\text { Available Online: } \\
\text { 10 June } 2020\end{array}$ \\
\hline
\end{tabular}

Physical properties of cotton bolls play a very important role in designing a cotton picker or cotton harvester. The various physical properties of cotton bolls viz., weight, size, volume, density, moisture content and force required to pick cotton bolls from plants were measured. The mean weight of bolls was $4.24 \mathrm{gm}$ and ranged from 3.15 to $7.74 \mathrm{gm}$. The mean diameter was $37.03 \mathrm{~mm}$ and ranged from 27.39 to $47.91 \mathrm{~mm}$. The mean volume of cotton boll was $29082.23 \mathrm{~mm} 3$ and average ranged from 20544.16 to $54658.77 \mathrm{~mm} 3$. Density of cotton boll was calculated by dividing theoretical weight of cotton boll with its volume. The mean value of density of cotton boll was $0.000147 \mathrm{~g} / \mathrm{mm} 3$ and ranged from 0.000126 to 0.000192 $\mathrm{g} / \mathrm{mm} 3$. The moisture content ranged from 5.0 to 8.6 per cent. It was observed that average force $3.14 \mathrm{~N}(320.7 \mathrm{~g})$ was required to pick the cotton bolls.

\section{Introduction}

Cotton is an International crop grown by about 80 countries across the world. On an average, cotton is planted in an area of 329.49 lakh hectares. India is at top with $1^{\text {st }}$ rank by contribution of 33.23 per cent in total area of the world. China is at $2^{\text {nd }}$ position by contributing 16.02 per cent area. The USA,
Pakistan, Uzbekistan and Brazil countries rank $3^{\text {rd }}, 4^{\text {th }}, 5^{\text {th }} \& 6^{\text {th }}$ by contributing $11.27,9.01$, 4.06 and 3.09 percentage area, respectively (Anon, 2017).

On an average, about 1482.86 lakh bales of cotton produced per year in world. The highest contribution was of China (28.30 per cent), followed by India (22.67 per cent), USA 
(13.59 per cent), Pakistan (8.14 per cent), Brazil (5.95 per cent) and Uzbekistan (3.93 per cent).

In India, Cotton is the second largest kharif crop, after rice contributing 6-7 per cent of the net sown area. The major portion of cotton is cultivated in Maharashtra, Gujarat, Punjab, Haryana, Rajasthan, Madhya Pradesh, Andhra Pradesh, Telangana, Karnataka and Tamil Nadu, besides, in small areas in nontraditional states like Uttar Pradesh, Orissa, West Bengal, Assam and Tripura. Based on cultivation, it is divided in three zone viz., North Zone, Central Zone and South Zone.

In North Zone is characterized by cotton grown totally as an irrigated crop in kharif season in the Indo-Gangetic Alluvial soils whereas Central Zone is characterized by hot semi-arid climate with mostly shallow to medium and deep black soils.

In South Zone, cotton is mostly grown in hot semi-arid regions, both as rainfed and irrigated cotton in medium black soil, red and black soils and coastal alluviums. Gujarat State comes under Central Zone, which is one of the largest cotton producing state with production of 11 million bales that is equivalent to $30 \%$ share in total production and is followed by Maharashtra and Andhra Pradesh.

Gujarat account for more than 30 per cent of the total cotton production in the country and has more than 30 Lakh hectares under cotton. The presence of black soils and annual rainfall of $80-100 \mathrm{~cm}$, make Gujarat a favourable region for cotton production.

Some of the major cotton producing regions of Gujarat are Bharuch, Vadodra, Panchmahal, Mehsana, Ahmedabad and Surendernagar. Hence, there is need to study the properties of cotton bolls which very useful to design and develop a cotton picker or harvesting machine.

\section{Materials and Methods}

The various physical properties of cotton bolls viz., weight, size, volume, density, moisture content and force required to pick cotton bolls from plants were measured at College of Renewable Energy and Environmental Engineering, Sardarkrrushinagar Dantiwada Agricultural University, Sardarkrushinagar, Gujarat. Fifty cotton bolls of GTHH-49 variety were randomly chosen for the experiment.

\section{Weight of cotton bolls}

Weight of picked cotton bolls were measured with the help of digital weighing machine with least count of $0.01 \mathrm{gm}$.

\section{Size (Equivalent diameter) of cotton bolls}

Size is the relative dimension, was measured by a using digital vernier calliper having a least count of $0.01 \mathrm{~mm}$. The dimensions of cotton bolls were measured along the three mutually perpendicular axes such as length, width and thickness and dimensions were noted in $\mathrm{mm}$. The equivalent diameter of open cotton bolls was determined by the following equation (Mohsenin, 1980).

Equivalent diameter $=(\mathrm{lbt})^{1 / 3} \ldots(1)$

Where, $1, b$ and $t$ are the maximum, intermediate and minimum perpendicular dimension, respectively.

\section{Volume}

A cylindrical box was used for determination of volume of cotton bolls. Cotton boll was pressed into the cylindrical box and height of boll was measured. Following equation was used for determination of volume of cotton bolls.

Volume $=\pi r^{2} h$ 
Where,

$\mathrm{r}=$ radius of cylindrical box $(\mathrm{mm})$

$\mathrm{h}=$ height of cotton boll pressed into the cylindrical box $(\mathrm{mm})$

\section{Density}

The density of cotton bolls were determined by dividing weight of cotton boll with its volume. It was expressed in $\mathrm{g} / \mathrm{mm}^{3}$ (Mohsenin, 1980).

\section{Moisture content}

Moisture content of picked cotton bolls were measured the help of digital moisture meter having $0.1 \%$ resolution and 2 pin moisture electrode probe.

\section{Picking force requirement}

For measuring the cotton picking force, a test setup was developed as shown in Fig 1. The setup consisted of a circular framed with 100 $\mathrm{mm}$ diameter and $150 \mathrm{~mm}$ height was used to measure cotton picking force.

It was fabricated from $5 \mathrm{~mm}$ diameter MS rods. A clamp has been fixed at the top centre of the frame having nut and bolt arrangement, which used to hold the fully opened cotton bolls. The developed frame was directly mounted on the weighing machine of an electronic balance.

As shown in Plate. 3.3, the fully opened cotton boll facing downward was placed in the clamp and bolt was tightened. A downward pulling was applied with fingers.

Hence, the force required to detach cotton from cotton bract was transmitted to weighing pan of an electronic balance through circular structure. The picking force measurement rig simulates the actual field condition during cotton picking (Murugesan and Manojkumar, 1999).

\section{Results and Discussion}

The various physical properties of cotton bolls viz., weight size, volume, density, moisture content and force required to pick cotton bolls were measured as per the procedures explained.

\section{Weight of cotton boll}

The weight of open cotton bolls is most important parameter in collection and storage of cotton bolls in the collection drum. Table 1 shows variation in weight of different cotton bolls. The mean weight of bolls of $4.24 \mathrm{gm}$ and ranged from 3.15 to $7.74 \mathrm{gm}$.

\section{Size (equivalent diameter) of cotton boll}

The equivalent diameter was calculated from length, width and thickness of open cotton boll. Table 1 shows that, the equivalent diameter increased with the increase in moisture content level. The mean diameter was $37.03 \mathrm{~mm}$ and ranged from 27.39 to 47.91 $\mathrm{mm}$.

\section{Volume of cotton boll}

The mean volume of cotton boll was 29082.23 $\mathrm{mm}^{3}$ and average ranged from 20544.16 to $54658.77 \mathrm{~mm}^{3}$. From the Table 1 there was strong positive correlation of picking force with boll volume. Hence, the volume of cotton boll plays a major role in deciding picking force required to separate seed cotton from the boll (Murugesan and Kumar, 1999).

\section{Density of cotton boll}

Density of cotton boll was calculated by dividing theoretical weight of cotton boll with 
its volume. Table 1 showed that the mean $\mathrm{g} / \mathrm{mm}^{3}$ and ranged from 0.000126 to 0.000192 value of density of cotton boll was $0.000147 \mathrm{~g} / \mathrm{mm}^{3}$.

Fig.1 Layout of picking force measurement frame

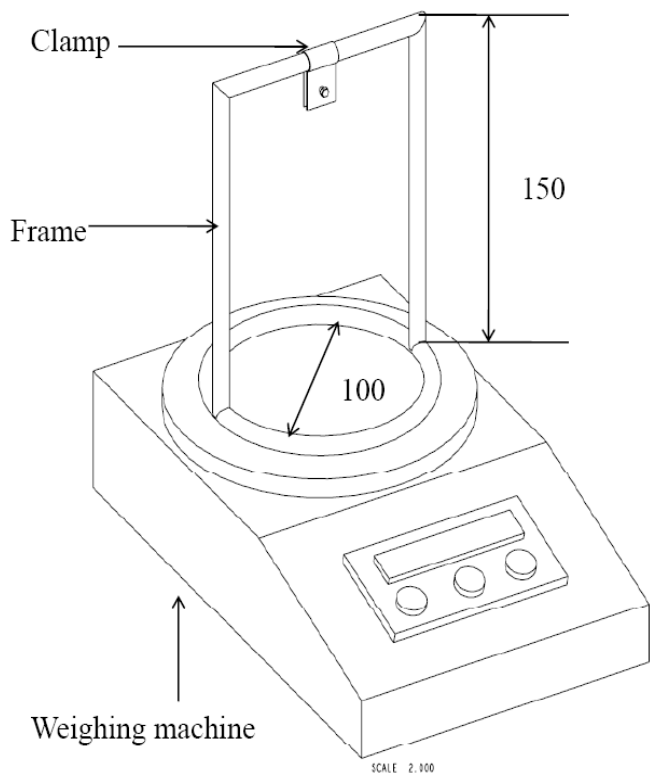

All dimensions are in $\mathrm{mm}$

Table.1 Physical properties of cotton bolls

\begin{tabular}{|c|c|c|c|c|c|c|}
\hline $\begin{array}{c}\text { Sample } \\
\text { No. }\end{array}$ & $\begin{array}{c}\text { Weight } \\
\mathbf{( g )}\end{array}$ & $\begin{array}{c}\text { Equivalent } \\
\text { Diameter }(\mathbf{m m})\end{array}$ & $\begin{array}{c}\text { Volume } \\
\left(\mathbf{m m}^{\mathbf{3}} \mathbf{)}\right.\end{array}$ & $\begin{array}{c}\text { Density } \\
\left(\mathbf{g} / \mathbf{m m}^{\mathbf{3}} \mathbf{)}\right.\end{array}$ & $\begin{array}{c}\text { Moisture } \\
\text { Content } \\
(\mathbf{\%})\end{array}$ & $\begin{array}{c}\text { Picking } \\
\text { force } \\
(\mathbf{g})\end{array}$ \\
\hline $\mathbf{1}$ & 4.04 & 30.52 & 30156.56 & 0.000134 & 5.3 & 310 \\
\hline $\mathbf{2}$ & 3.71 & 30.65 & 28648.73 & 0.000129 & 5.5 & 308 \\
\hline $\mathbf{3}$ & 3.55 & 31.71 & 24690.68 & 0.000144 & 6.3 & 352 \\
\hline $\mathbf{4}$ & 5.00 & 35.87 & 30910.47 & 0.000162 & 7.8 & 293 \\
\hline $\mathbf{5}$ & 3.15 & 27.39 & 25067.64 & 0.000126 & 5.0 & 339 \\
\hline $\mathbf{6}$ & 3.57 & 32.22 & 26575.47 & 0.000134 & 6.7 & 333 \\
\hline $\mathbf{7}$ & 4.05 & 33.31 & 28271.78 & 0.000143 & 6.9 & 315 \\
\hline $\mathbf{8}$ & 7.74 & 34.27 & 54658.77 & 0.000142 & 7.1 & 249 \\
\hline $\mathbf{9}$ & 3.62 & 31.79 & 27894.82 & 0.000130 & 6.4 & 332 \\
\hline $\mathbf{1 0}$ & 3.77 & 30.84 & 28083.30 & 0.000134 & 5.4 & 314 \\
\hline $\mathbf{1 1}$ & 4.80 & 39.38 & 35810.92 & 0.000134 & 7.9 & 275 \\
\hline $\mathbf{1 2}$ & 4.63 & 35.74 & 32041.35 & 0.000145 & 7.7 & 288 \\
\hline $\mathbf{1 3}$ & 6.06 & 43.48 & 41465.27 & 0.000146 & 8.3 & 259 \\
\hline
\end{tabular}




\begin{tabular}{|c|c|c|c|c|c|c|}
\hline $\mathbf{1 4}$ & 3.76 & 35.17 & 22617.42 & 0.000166 & 7.5 & 367 \\
\hline $\mathbf{1 5}$ & 4.89 & 36.05 & 25444.60 & 0.000192 & 7.6 & 334 \\
\hline $\mathbf{1 6}$ & 3.92 & 36.98 & 24313.73 & 0.000161 & 7.6 & 348 \\
\hline $\mathbf{1 7}$ & 4.52 & 36.40 & 30533.52 & 0.000148 & 7.8 & 295 \\
\hline $\mathbf{1 8}$ & 5.27 & 40.02 & 33549.17 & 0.000157 & 8.1 & 281 \\
\hline $\mathbf{1 9}$ & 4.40 & 40.88 & 29591.12 & 0.000149 & 8.1 & 297 \\
\hline $\mathbf{2 0}$ & 3.91 & 32.67 & 22051.98 & 0.000177 & 5.8 & 377 \\
\hline $\mathbf{2 1}$ & 4.56 & 37.16 & 35810.92 & 0.000127 & 8.0 & 279 \\
\hline $\mathbf{2 2}$ & 3.75 & 32.27 & 27894.82 & 0.000134 & 5.7 & 327 \\
\hline $\mathbf{2 3}$ & 3.74 & 39.46 & 25256.12 & 0.000148 & 7.5 & 341 \\
\hline $\mathbf{2 4}$ & 3.63 & 39.19 & 23748.29 & 0.000153 & 7.4 & 355 \\
\hline $\mathbf{2 5}$ & 5.34 & 43.19 & 35433.96 & 0.000151 & 8.2 & 273 \\
\hline $\mathbf{2 6}$ & 4.48 & 40.51 & 32606.78 & 0.000137 & 8.0 & 334 \\
\hline $\mathbf{2 7}$ & 5.30 & 44.65 & 34114.61 & 0.000155 & 8.5 & 290 \\
\hline $\mathbf{2 8}$ & 4.01 & 33.11 & 29214.17 & 0.000137 & 5.8 & 298 \\
\hline $\mathbf{2 9}$ & 4.17 & 39.96 & 31475.91 & 0.000132 & 7.8 & 296 \\
\hline $\mathbf{3 0}$ & 3.93 & 37.03 & 23936.77 & 0.000164 & 7.7 & 360 \\
\hline $\mathbf{3 1}$ & 3.20 & 36.13 & 22051.98 & 0.000145 & 7.5 & 379 \\
\hline $\mathbf{3 2}$ & 3.48 & 37.11 & 22994.38 & 0.000151 & 7.7 & 369 \\
\hline $\mathbf{3 3}$ & 3.95 & 37.56 & 26763.95 & 0.000148 & 7.8 & 336 \\
\hline $\mathbf{3 4}$ & 4.43 & 36.02 & 31475.91 & 0.000141 & 7.5 & 343 \\
\hline $\mathbf{3 5}$ & 4.16 & 38.25 & 30156.56 & 0.000138 & 7.9 & 308 \\
\hline $\mathbf{3 6}$ & 3.84 & 35.94 & 23182.86 & 0.000166 & 7.2 & 357 \\
\hline $\mathbf{3 7}$ & 4.19 & 37.39 & 29591.12 & 0.000142 & 7.4 & 321 \\
\hline $\mathbf{3 8}$ & 5.58 & 38.98 & 36941.79 & 0.000151 & 7.8 & 269 \\
\hline $\mathbf{3 9}$ & 3.43 & 38.37 & 20921.11 & 0.000164 & 7.8 & 383 \\
\hline $\mathbf{4 0}$ & 3.47 & 36.66 & 20732.64 & 0.000167 & 7.4 & 388 \\
\hline $\mathbf{4 1}$ & 5.07 & 47.91 & 37695.70 & 0.000134 & 8.6 & 254 \\
\hline $\mathbf{4 2}$ & 3.30 & 36.93 & 24690.68 & 0.000134 & 7.3 & 355 \\
\hline $\mathbf{4 3}$ & 3.89 & 41.50 & 28271.78 & 0.000138 & 8.0 & 317 \\
\hline $\mathbf{4 4}$ & 3.55 & 35.34 & 20544.16 & 0.000173 & 7.2 & 397 \\
\hline $\mathbf{4 5}$ & 3.89 & 43.79 & 25444.60 & 0.000153 & 8.0 & 329 \\
\hline $\mathbf{4 6}$ & 3.95 & 43.02 & 27140.90 & 0.000146 & 8.1 & 321 \\
\hline $\mathbf{4 7}$ & 3.82 & 41.20 & 25256.12 & 0.000151 & 7.9 & 345 \\
\hline $\mathbf{4 8}$ & 4.78 & 37.86 & 32606.78 & 0.000147 & 6.9 & 279 \\
\hline $\mathbf{4 9}$ & 4.01 & 36.57 & 31287.43 & 0.000128 & 7.1 & 290 \\
\hline $\mathbf{5 0}$ & 4.67 & 32.89 & 34491.57 & 0.000135 & 6.7 & 276 \\
\hline $\mathbf{M e a n}$ & 4.24 & 37.03 & 29082.23 & 0.000147 & 7.3 & 320.7 \\
\hline $\mathbf{M a x}$ & 7.74 & 47.91 & 54658.77 & 0.000192 & 8.6 & 397 \\
\hline $\mathbf{M i n}$ & 3.15 & 27.39 & 20544.16 & 0.000126 & 5.0 & 249 \\
\hline & & & & & & \\
\hline
\end{tabular}




\section{Moisture content of cotton boll}

The mean moisture content of cotton boll was 7.3 per cent and ranged from 5.0 to 8.6 per cent.

\section{Picking force measurement}

The force required to pick the cotton from the fully opened bolls was measured with the help of electronic balance through circular frame as shown in Fig. 1.

It was observed that average force $3.14 \mathrm{~N}$ $(320.7 \mathrm{~g})$ was required to pick the cotton bolls. Murugesan and Kumar (1999) observed maximum picking force of $3.456 \mathrm{~N}$ for Anjali variety. Table 1 shows that the range of picking force varied from $2.44 \mathrm{~N}(249 \mathrm{~g})$ to $3.89 \mathrm{~N}(397 \mathrm{~g})$.

\section{References}

Anonymous (2017). Directorate of Cotton Development, Government of India. Status Paper of Indian Cotton. New Delhi, India. pp. 211.

Mohsenin, N. N. (1980). Physical properties of plant and animal materials. Gordon and Breach Science Publishers, N W, New York.

Murugesam, R. and Manojkumar, T. S. (1999). Picking force measurement of some cotton varieties. Agricultural Engineering Today. 23(5-6): 56-62.

\section{How to cite this article:}

Alok Gora, R. N. Singh and Jaypalsinh Chavda. 2020. Physical Properties of Cotton Bolls (GTHH-49). Int.J.Curr.Microbiol.App.Sci. 9(06): 4064-4069. doi: https://doi.org/10.20546/ijcmas.2020.906.475 